\title{
Host and parasite population structure in a natural plant-pathogen system
}

\author{
FRANÇOIS DELMOTTE* $\dagger$, ERIKA BUCHELI $\$$ \&ACOUI A. SHYKOFF†† \\ $\dagger$ Laboratoire d'Evolution et Systématique, CNRS URA 2154, Université Paris-sud, 91045 Orsay Cedex, France and \\ $\$$ Experimental Ecology, ETH-Zurich, ETHZ-NW, 8092 Zurich, Switzerland
}

\begin{abstract}
We investigated the genetic population structure in a metapopulation of the plant Silene latifolia (Caryophyllaceae) and its fungal pathogen Microbotryum violaceum (Ustilaginales), a pollinatorborne disease. Population structure of the host plant was estimated using allozyme markers and that of the fungus by microsatellites. Both host and parasite showed significant differentiation, but parasite populations were 12 times more strongly differentiated than those of the hosts. We found significant isolation by distance for host populations but not for parasite populations. Higher population differentiation for the parasite may result from small effective population size, high selfing rates, or low migration rate. In this system, hosts are obligate outcrossers and they migrate by seeds and pollen, whereas parasites can self-fertilize and migrate only on pollinating insects. We discuss the effect of limited gene flow in this parasite on its coevolutionary interaction with its host, and its potential for local adaptation on sympatric host populations.
\end{abstract}

Keywords: gene flow, local adaptation, mating system, Microbotryum (=Ustilago) violaceum, metapopulation, Silene latifolia.

\section{Introduction}

Host-parasite systems involve coevolutionary conflicts, where hosts are selected to evolve new resistance and parasites to evolve new pathogenicity. Therefore the biotic aspect of the environment of both players continuously degenerates. The rate of this degeneration depends on the relative evolutionary rates of host and parasite. If parasites evolve faster than their hosts, hosts will lag behind in this coevolutionary conflict. If hosts evolve faster, parasites will lag behind. These lags result from coevolution between sympatric hosts and their parasites and give rise to patterns of locally adapted or maladapted parasites (Kaltz \& Shykoff, 1998).

Though parasites often evolve faster than hosts on account of shorter generation times and high mobility (Hamilton et al., 1990), Thompson (1994) pointed out that migration between host populations in a patchy environment could spread host adaptations to counter this evolutionary advantage usually enjoyed by parasites. Gene flow, i.e. the movement of gametes or individuals among populations, may have two roles in

*Correspondence and present address: Laboratoire de Zoologie, INRA, Centre de recherche de Rennes, B.P. 29, 35653 Le Rheu, France. E-mail: delmotte@rennes.inra.fr the differentiation of local populations. It can homogenize populations, thereby preventing adaptation to local conditions (Slatkin, 1985; Dias, 1996), or it can spread new genes or combinations of genes across populations, actually accelerating evolution by importing evolutionary novelties or re-establishing alleles that have been lost by drift (Slatkin, 1985; Thompson, 1994).

Price (1980) granted population structure a central role in the ecological and evolutionary interplay between hosts and parasites, seeing parasite populations as strongly structured and connected by little gene flow. Parasite populations are, however, not always strongly structured (see Nadler, 1995 for review). Populations of plant pathogens in agricultural systems show weak though significant genetic structure for neutral markers, and somewhat stronger structure for virulence factors (see McDermott \& McDonald, 1993 for review).

Most relevant to the coevolutionary process, however, is the population structure of both host and parasite. Recent theoretical formalizations of coevolution in a metapopulation context find different coevolutionary outcomes under different regimes of migration of hosts and parasites. When parasites migrate more than hosts within a metapopulation, the more common situation of locally adapted parasites (Kaltz \& Shykoff, 1998) is expected, with higher parasite relative fitness in sympatry than in allopatry. On the other hand, when host 
populations are connected by higher rates of gene flow than are parasite populations, parasites may have lower relative fitness on their local sympatric hosts (Gandon et al., 1996). Therefore, in order to predict the outcome of the coevolutionary conflict between host and parasites or to interpret patterns of local adaptation, it is important to have information on the population structure of the two players.

The burgeoning literature on coevolution takes the effect of population structure more and more into consideration, but unfortunately, to date, only few investigations have determined the population structure of both hosts and parasites. Comparisons of host and parasite population structures reveal no clear pattern as to whether host or parasite populations generally exchange the more genes. White-tailed deer (Odocoileus virginianus) and their liver fluke parasite (Fascioloides magna) have comparable degrees of population subdivision, suggesting similar amounts of genetic exchange among host and parasite populations (Mulvey et al., 1991). For seed-eating weevils (Larinus cynarae) on thistles (Onopordum illyricum) in southern Europe (Michalakis et al., 1994) and trematode parasites (Microphallus sp.) of snails (Potamopyrgus antipodarum) in New Zealand (Dybdahl \& Lively, 1996), populations of hosts show greater subdivision than those of parasites. In contrast, the great-spotted cuckoo (Clamator glandarius), a brood parasite, is far more philopatric, having stronger population structure than its magpie host (Pica pica) in populations sympatric with these brood parasites (Martinez et al., 1999).

Here, we investigated the genetic population structure of hosts and parasites in a natural metapopulation network. The host plant, Silene latifolia, is a weedy, dioecious perennial with ephemeral populations that correspond to a metapopulation (Antonovics et al., 1994; McCauley, 1997), and is the host of the anther smut fungus Microbotryum (=Ustilago) violaceum. This fungus is transported from diseased to healthy plants by insects that usually serve as pollinators for its host plants (Baker, 1947; Roche et al., 1995), and so has the dynamics of a sexually transmitted disease. The disease sterilizes but does not kill its host plants. Seeds are never infected in this system (Baker, 1947). Therefore host genes can migrate between populations via seeds or pollen carried by pollinators, but parasite genes are moved only by pollinators that bear spores. Furthermore, pollinators discriminate against diseased plants (Shykoff \& Bucheli, 1995), so there are a priori reasons to expect that gene flow might be lower between parasite populations than between host populations. Because rates of migration within a host-parasite metapopulation will influence the evolutionary potential of hosts and parasites (Gandon et al., 1996), this study will allow predictions about local adaptation of parasites or hosts in this natural system.

\section{Materials and methods}

\section{Sampling design}

During peak flowering in the summer of 1994, fungal spores were collected on $S$. latifolia from five populations in the region of the Rhine Valley from France, Germany and Switzerland (Fig. 1). Although plants may rarely be infected by multiple fungal strains, single flowers from multiply infected plants usually contain only a single fungal strain (Day, 1980). Therefore a single unopened flower bud from each plant was collected individually into a microcentrifuge tube and left to dry. Spores were shaken out of the dried flower into the tube, sealed, and stored at room temperature until DNA extraction.

Plant material was collected in the spring of 1997 from nine populations growing in the same region as the fungal populations. Young leaves from randomly chosen plants were collected into cellophane bags. Leaves were stored on dry ice for one day until extraction. Proteins were extracted by grinding leaves in a buffer $(0.2 \mathrm{~m}$ Tris- $\mathrm{HCl} \mathrm{pH} 6.5$ with $1.6 \mathrm{mg}$ dithioerythritol, $1.2 \mathrm{mg}$ cysteine, $5 \mathrm{mg}$ EDTA $\left(\mathrm{Na}_{2}\right)$ and $10 \mathrm{mg}$ PVP per $\mathrm{mL}$ ). Samples in microcentrifuge tubes were centrifuged at $7900 \mathrm{~g}$ for $10 \mathrm{~min}$ and then frozen at $-80^{\circ} \mathrm{C}$ until electrophoresis.

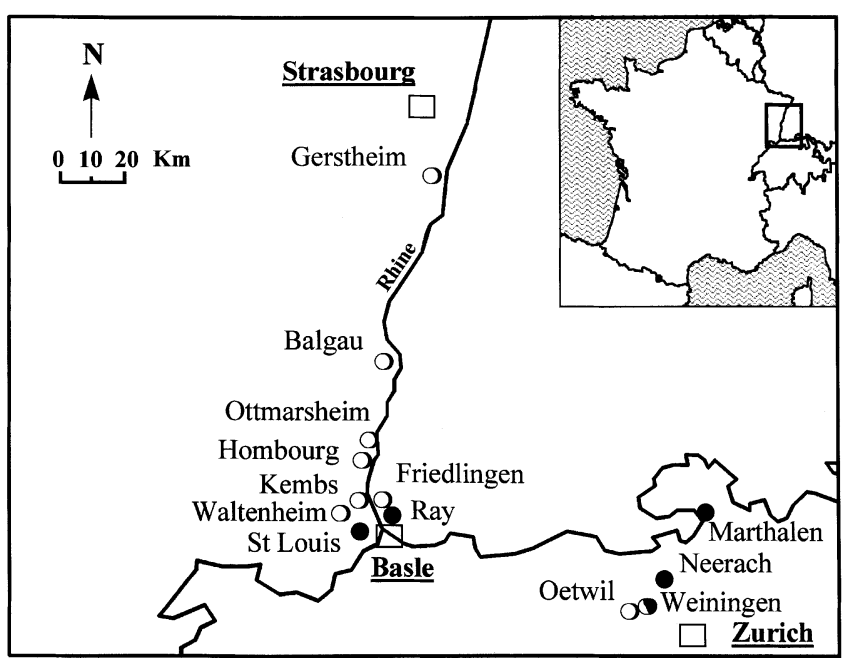

Fig. 1 Map of the Rhine Valley: white circles $(O)$ indicate host-plant populations of Silene latifolia, black circles $(\mathbf{O})$ indicate the parasite populations of the fungus Microbotryum violaceum, and the half white and black circle indicates a population of both the host and the parasite. 
The metapopulation of host and parasite in this study has been stable over time, with little change in population size or disease prevalence, i.e. proportion of plants infected, in the populations followed for several years. We thus consider that the difference in collecting dates for parasites and hosts does not seriously bias the sampling design.

\section{Electrophoretic techniques}

For the plants, 15 enzyme systems were tested and four were retained as informative. We used 6PGD (6phosphogluconic dehydrogenase, EC 1.1.1.44), PGI (glucose-6-phosphate isomerase, EC 5.3.1.9), DIA (diaphorase, EC 1.8.1.4) and IDH (isocitrate dehydrogenase, EC 1.1.1.42) (Pasteur et al., 1987; Soltis \& Soltis, 1989). These four enzyme systems provided five informative polymorphic loci because two loci could be read for 6PGD.

Protein samples were loaded onto $13 \%$ starch gels containing 3\% sucrose mixed with histidine buffer $\mathrm{pH}$ 6.5. Alleles were scored by eye according to their mobility in the electric field. Mendelian segregation of alleles was not investigated but is known, at least for the PGI system, from closely related species (Prentice \& Giles, 1993).

\section{Microsatellite markers}

No polymorphism among fungal strains was detected by electrophoresis techniques, so five polymorphic microsatellite loci (L6, L11, L14, L17 and L18) were used. For a detailed description of their identification and amplification methods, see Bucheli et al. (1998).

\section{Statistical analysis}

Levels of polymorphism for both the host and the parasite were investigated using BIOsys-1 (Swofford \& Selander, 1981).

Before testing the deviation from Hardy-Weinberg genotype frequencies, global linkage disequilibrium between pairs of loci was tested using a Fisher exact test for each locus and computing (Markov chain method) an unbiased estimate of the exact probability using GENEPOP-1.3 (Raymond \& Rousset, 1995). Deviations from Hardy-Weinberg expectations were then tested using the same software. A Fisher's combined probability test was performed to assess the overall significance of multiple tests across all loci and populations. Wherever necessary, levels of significance of multiple tests were corrected by the sequential Bonferroni method described by Rice (1989).

To study genetic differentiation among plant populations, we used Wright's $F$-statistics, which decompose the observed deviation from Hardy-Weinberg expectations into an intrapopulation deviation $\left(F_{\mathrm{IS}}\right)$ and an interpopulation deviation $\left(F_{\mathrm{ST}}\right)$. These statistics were estimated using FSTAT-1.2 (Goudet, 1995) which calculates Weir and Cockerham's unbiased estimators (Weir \& Cockerham, 1984). To test the significance of the $F$-statistics, we carried out 8000 permutations of alleles or genotypes. Alleles were permuted within populations to test the significance of $F_{\text {IS. }}$. If $F_{\text {IS }}$ was not significant then the significance of $F_{\mathrm{ST}}$ was tested by permuting alleles among populations. For significant cases of $F_{\mathrm{IS}}$, multilocus genotypes were permuted among populations to test the significance of $F_{\mathrm{ST}}$. To calculate the standard errors for the $F$-statistics jackknifing was performed for each locus among samples, omitting one sample at a time, and recalculating the different $F$-statistics from this reduced data set.

The genetic structure of fungal populations was assessed by using both Weir \& Cockerham's parameters (1984) and Michalakis \& Excoffier's (1996) analysis of molecular variance (AMOVA). The latter analysis follows Slatkin's (1995) estimation of genetic differentiation for single-locus data $\left(R_{\mathrm{ST}}\right)$ that takes length differences between microsatellite alleles into account. GENEPOP-1.3 (Raymond \& Rousset, 1995) runs the AMOva and gives $\rho$-statistics equivalent to $F$-statistics but especially developed for microsatellite markers.

For both the host and the parasite, we tested isolation by distance by computing a Mantel test between the two half-matrices of pairwise $F_{\mathrm{ST}}$ and pairwise geographical distances. Pairwise geographical distances were calculated as linear distances along the Rhine Valley assuming dispersal along this valley. For the host plants, we plotted the relationship between $F_{\mathrm{ST}} /\left(1-F_{\mathrm{ST}}\right)$ and geographical distance for pairs of populations (Rousset \& Raymond, 1997).

\section{Results}

\section{General polymorphism}

Nine populations of $S$. latifolia with a mean (range) sample size of 31.8 (29-39) individuals per population and five populations of $M$. violaceum with a mean (range) sample size of 17.3 (13-29) individuals per population were analysed. In fungal populations with low infection prevalence, all available strains were sampled. Indeed, stable low disease prevalence characterizes this host-parasite metapopulation, with median disease prevalence of 0.05 and a maximum of 0.51 from 14 populations in 1996 (Kaltz et al., 1999).

Electrophoresis of the plant samples detected between three (Dia, 6Pgd-1, Idh) and four (6Pgd-2, Pgi) alleles (mean $=3.4)$ at the different loci. For Idh and Dia, the 
frequency of the most common allele was greater than $95 \%$. In the fungal populations, microsatellite markers revealed two alleles at the $L 11$ and $L 17$ loci, and three at the L6, L14 and L18 loci.

\section{Hardy-Weinberg proportions}

No linkage disequilibrium between any pair of loci was found for the host populations or for those loci (i.e. L18, $L 6, L 14)$ that were testable in the parasite populations. The remaining two microsatellite loci (i.e. L11, L17) were not sufficiently variable to test for linkage disequilibrium.

In the plant populations, we found no deviation from Hardy-Weinberg proportions except at the Pgi locus in the Kembs and Gerstheim populations (Table 1). Nevertheless, the combined Fisher's test was significant $(P=0.006)$ only for the Kembs population. When we eliminated the locus Pgi from the Kembs population data set, the Fisher's test across loci for this population was no longer significant $(P>0.9)$. The same was true for the global test across all loci and all populations $(P=0.26)$. The most common allele in the Kembs population was rare in all other populations and particularly rare in those closest to Kembs. This population is not distinct geographically, lying in the centre of our metapopulation, so no a priori explanation for its different genetical behaviour at the Pgi locus can be invoked. Because the Kembs population was genetically distinct from all others, we reduced the data set by removing this population, causing the global $F_{\text {IS }}$ across loci and populations to fall from 0.092 to 0.05 , which was no longer significant (Table 2).

In the fungal populations, microsatellite loci were not highly variable and were often homozygous. Combined Fisher's tests across loci and populations did not detect deviations from Hardy-Weinberg proportions (Table 3). However, the power of the test was low because of small sample sizes. $F_{\text {IS }}$ values, when they could be calculated, were always very high in all populations (Table 3 ) and highly significant across populations and loci $\left(F_{\mathrm{IS}}=0.635, P<0.001\right.$; Table 2$)$.

\section{Differentiation among populations}

In plant populations along the Rhine Valley, we found a significant $(P<0.001)$ global $F_{\mathrm{ST}}$ of $0.125 \pm 0.076$ (SE). Without the Kembs population, the global $F_{\mathrm{ST}}$ was reduced to $0.076 \pm 0.016$, but remained significant $(P<0.001 ;$ Table 2). To investigate the geographical scale of population differentiation, we carried out a spatially hierarchical analysis of genetic structure of the host plant populations, considering the three general regions of Zurich, Basle and Strasbourg (Table 4). The
Strasbourg region contained a single population (Gerstheim), so $F_{\mathrm{ST}}$ values could not be calculated. Significant structure was detected at most spatial levels considered, but the $F_{\mathrm{ST}}$ values within the two regions of Basle and Zurich were lower than the $F_{\mathrm{ST}}$ for all populations of the three regions. Gene flow appears to be limited by geographical separation, confirmed by the significant isolation by geographical distance (Mantel test, $P=0.005$ ) along the Rhine valley (Fig. 2).

The five fungal populations showed very strong differentiation (Table 2). The global $F_{\mathrm{ST}}$ value was greater than $0.9(P<0.001)$, partly because of too low intrapopulation polymorphism. Indeed, we never found more than three multilocus genotypes in any population, and two populations of the five analysed comprised the same multilocus genotypes (Table 5). No isolation by distance was found for the fungal populations (Mantel test, $P=0.1$ ).

\section{Discussion}

\section{Within-population polymorphism}

Within-population variation found for the host plants (Silene latifolia) was greater than that found for the parasite (Microbotryum violaceum). Fungal populations were always smaller than plant populations, and this smaller population size could explain lower polymorphism. Furthermore, low allozyme variation for this and related fungi has been previously reported (Antonovics et al., 1996), suggesting that other factors, such as a highly selfing mating system (Bucheli, unpubl. data) may reduce the neutral variation in these parasite populations.

Fungal populations showed excess homozygotes, as demonstrated by the highly significant global $F_{\text {IS }}$ (Table 2). Indeed, over the five populations, only $6 \%$ of individuals $(N=100)$ were heterozygous for at least one locus. Because this fungus is transmitted by insect pollinators (Baker, 1947; Roche et al., 1995) that prefer healthy over diseased plants (Shykoff \& Bucheli, 1995), spore mixtures may seldom arrive on a flower because spore deposition events are rare. Thus, the opportunity for outcrossing between fungal strains is restricted. Furthermore, little outcrossing occurs even when mixtures of spores of $M$. violaceum are deposited on flowers (Baird \& Garber, 1979), perhaps because of preferential conjugations between selfing combinations of haploid fungal sporidia (Kaltz \& Shykoff, 1999).

Selfing may reduce genetic variation directly by reducing effective population size, and indirectly by reducing recombination among loci. Increasing linkage disequilibrium increases the exposure of neutral markers to selection on linked loci. Neutral variation can 
Table 1 Allele frequencies for each locus and each population of Silene latifolia (sample size is given in parentheses). Alleles are coded with letters. The exact probability of the test for deviation from Hardy-Weinberg proportions $\left(\mathrm{H}_{0}\right.$ : random association of gametes) is indicated by HW. Combined Fisher's test was used to test for deviation from Hardy-Weinberg proportions across populations and loci. Probabilities that were significant after sequential Bonferroni corrections (Rice, 1989) are given in bold type. Probabilities recalculated on the reduced data set after removing the data of locus Pgi of the Kembs population are presented in square brackets. indicates that statistics could not be estimated. $F_{\text {IS }}$ is given for each population

\begin{tabular}{|c|c|c|c|c|c|c|c|c|c|c|c|c|}
\hline \multirow[b]{2}{*}{ Locus } & \multirow[b]{2}{*}{ Alleles } & \multirow[b]{2}{*}{ Tests } & \multicolumn{9}{|c|}{ Populations } & \multirow{2}{*}{$\begin{array}{c}\text { All populations } \\
\text { HW }\end{array}$} \\
\hline & & & Waltenheim & Friedlingen & Hombourg & Ottmarsheim & Balgau & Weiningen & Oetwil & Kembs & Gerstheim & \\
\hline \multicolumn{13}{|l|}{ Dia } \\
\hline & & & $(36)$ & $(35)$ & $(31)$ & $(36)$ & $(32)$ & $(31)$ & $(31)$ & $(31)$ & (15) & \\
\hline & $A$ & & 0.986 & 0.986 & 1 & 0.958 & 0.984 & 1 & 0.903 & 0.984 & 1 & \\
\hline & $B$ & & & 0.014 & & 0.014 & & & 0.065 & & & \\
\hline & $C$ & & 0.014 & & & 0.028 & 0.016 & & 0.032 & 0.016 & & \\
\hline & & HW & $\sim$ & $\sim$ & $\sim$ & 1 & $\sim$ & $\sim$ & 1 & $\sim$ & $\sim$ & 1 \\
\hline \multicolumn{13}{|l|}{$6 P g d-1$} \\
\hline & & & $(37)$ & (33) & $(29)$ & $(35)$ & $(31)$ & $(31)$ & $(32)$ & $(31)$ & (13) & \\
\hline & $A$ & & 0.865 & 1 & 0.966 & 0.971 & 1 & 0.984 & 0.875 & 0.935 & 0.923 & \\
\hline & $B$ & & 0.014 & & & 0.029 & & & 0.016 & 0.016 & & \\
\hline & $C$ & & 0.122 & & 0.034 & & & 0.016 & 0.109 & 0.048 & 0.077 & \\
\hline & & HW & 0.1045 & $\sim$ & 1 & 1 & $\sim$ & $\sim$ & 0.3916 & 1 & 1 & 0.8951 \\
\hline \multicolumn{13}{|l|}{$6 P g d-2$} \\
\hline & $A$ & & 0.361 & 0.333 & 0.518 & 0.386 & 0.484 & 0.726 & 0.688 & 0.317 & 0.778 & \\
\hline & $B$ & & 0.167 & 0.061 & 0.179 & 0.143 & 0.081 & 0.113 & 0.047 & 0.05 & & \\
\hline & $C$ & & & 0.015 & & & 0.016 & & & & & \\
\hline & $D$ & & 0.472 & 0.591 & 0.304 & 0.471 & 0.419 & 0.161 & 0.266 & 0.633 & 0.222 & \\
\hline & & HW & 0.8183 & 0.5987 & 0.9056 & 0.1973 & 0.9578 & 0.375 & 1 & 0.7406 & 0.3412 & 0.9421 \\
\hline \multicolumn{13}{|l|}{$P g i$} \\
\hline & & & $(36)$ & (33) & $(31)$ & $(30)$ & $(30)$ & $(31)$ & $(31)$ & $(23)$ & $(20)$ & \\
\hline & $A$ & & 0.986 & 0.985 & 0.935 & 0.917 & 0.933 & 0.952 & 0.952 & 0.4 & 0.575 & \\
\hline & $B$ & & & & & & & & & 0.033 & & \\
\hline & $C$ & & 0.014 & 0.015 & 0.032 & 0.083 & 0.05 & 0.048 & 0.048 & 0.567 & 0.4 & \\
\hline & $D$ & & & & 0.032 & & 0.017 & & & & 0.025 & \\
\hline & & HW & $\sim$ & $\sim$ & 1 & 1 & 1 & 1 & 1 & 0.0002 & 0.0153 & 0.0272 \\
\hline \multirow[t]{8}{*}{$I d h$} & & & & & & & & & & & & $(0.7566)$ \\
\hline & & & (26) & (19) & $(30)$ & $(23)$ & (23) & (23) & $(25)$ & (32) & (16) & \\
\hline & $A$ & & 1 & 0.974 & 0.933 & 0.978 & 1 & 1 & 1 & 1 & 0.969 & \\
\hline & $B$ & & & 0.026 & 0.067 & & & & & & 0.031 & \\
\hline & $C$ & & & & & 0.022 & & & & & & \\
\hline & & HW & $\sim$ & $\sim$ & 0.1008 & $\sim$ & $\sim$ & $\sim$ & $\sim$ & $\sim$ & $\sim$ & $\sim$ \\
\hline & & All loci HW & 0.2958 & $\sim$ & 0.78 & 0.918 & 0.9991 & 0.7428 & 0.9846 & $\begin{array}{l}\mathbf{0 . 0 0 6} \\
{[0.963]}\end{array}$ & 0.1048 & $\begin{array}{l}\mathbf{0 . 0 1 0 5} \\
{[0.2607]}\end{array}$ \\
\hline & & $F_{\text {IS }}$ & 0.075 & 0.143 & 0.074 & -0.152 & -0.034 & 0.034 & 0.018 & 0.333 & 0.409 & $\begin{array}{l}0.092 \\
{[0.05]}\end{array}$ \\
\hline
\end{tabular}


Table $2 F$-statistics ( $\theta$ of Weir \& Cockerham, 1984) calculated over five populations of the parasite Microbotryum violaceum and eight populations (data without the Kembs population) of the host plant Silene latifolia. Standard errors (SE) were obtained by jackknifing across loci. Probabilities $\left(\mathrm{H}_{0}\right.$ : estimator different from 0) were obtained after 8000 permutations of alleles or multilocus genotypes. $\rho$-statistics which take allele size of the microsatellites into account were calculated with the method described by Michalakis \& Excoffier (1996)

\begin{tabular}{lcc}
\hline & $\begin{array}{c}F_{\mathrm{IS}} \pm \mathrm{SE} \\
\left(\rho_{\mathrm{IS}}\right)\end{array}$ & $\begin{array}{c}F_{\mathrm{ST}} \pm \mathrm{SE} \\
\left(\rho_{\mathrm{ST}}\right)\end{array}$ \\
\hline Parasite & $0.635 \pm 0.24 * * *$ & $0.904 \pm 0.038 * * *$ \\
& $(0.387)$ & $(0.958)$ \\
Host & $0.05 \pm 0.08$ & $0.076 \pm 0.016^{* * *}$ \\
\hline
\end{tabular}

$* * * P<0.001$. therefore be reduced by selection at linked loci by background selection (Nordborg et al., 1996) or selective sweeps (Stephan et al., 1992). Indeed, field studies reveal linkage disequilibria between selected loci and neutral markers in selfing (Parker, 1988) or clonally reproducing plants (Espiau et al., 1998). Low intrapopulation variability of the parasite could reflect recent strong selection for particular virulence genes.

\section{Among-population differentiation}

We found significant differentiation among our $S$. latifolia populations both with $\left(F_{\mathrm{ST}}=0.125\right)$ and without the Kembs population $\left(F_{\mathrm{ST}}=0.076\right)$, comparable to that found for established populations of the same species in North America $\left(F_{\mathrm{ST}}=0.128,95 \%\right.$ CI 0.059

Table 3 Allele frequencies for five microsatellite loci and five populations of Microbotryum violaceum (sample size is given in parentheses). The exact probability of the test for deviation from Hardy-Weinberg proportions $\left(\mathrm{H}_{0}\right.$ : random association of gametes) is given in the last line (HW). Combined Fisher's test was used to test for deviation from Hardy-Weinberg proportions across populations and across loci. $\sim$ indicates that statistics could not be estimated. $F_{\text {IS }}$ is given for each population

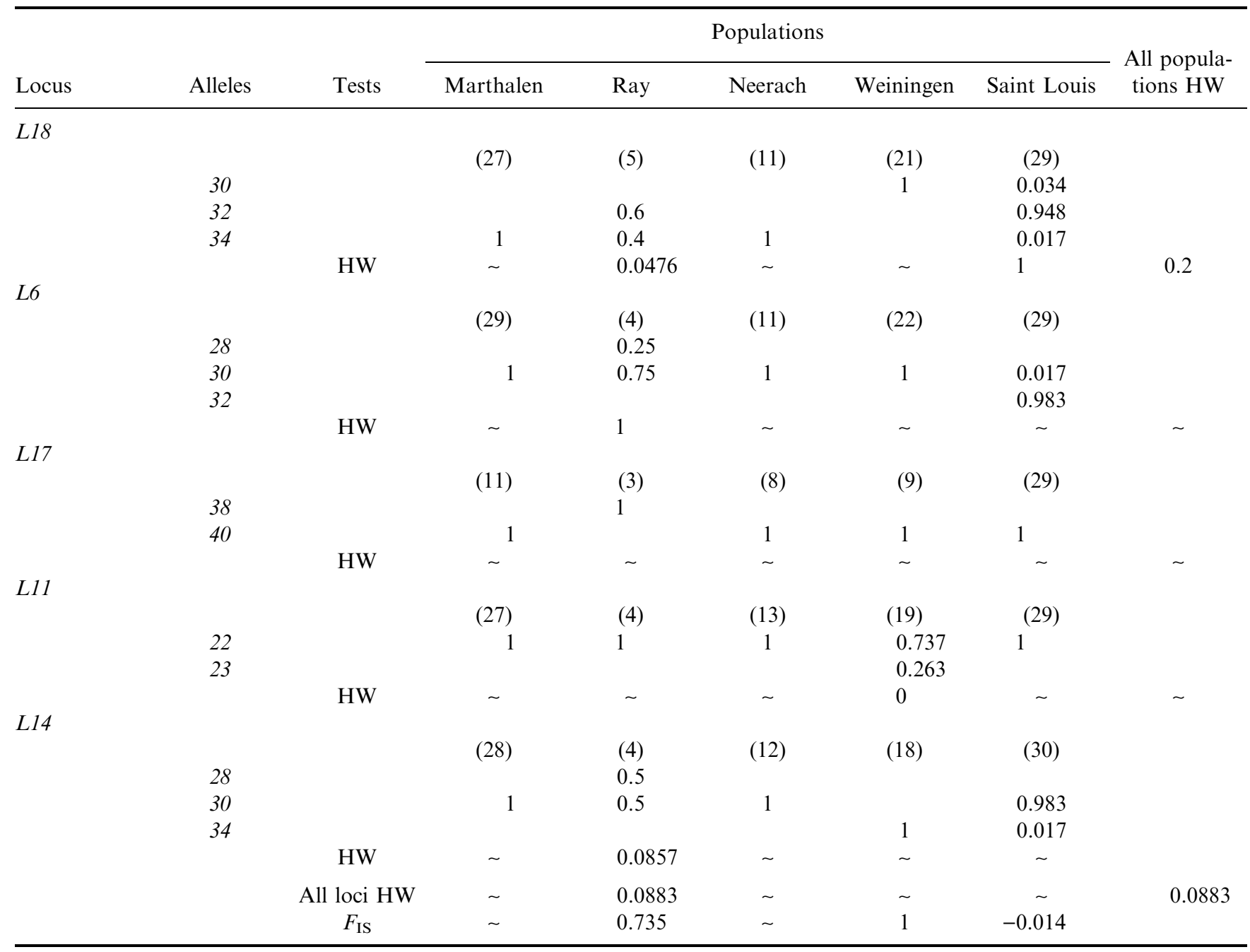

(C) The Genetical Society of Great Britain, Heredity, 82, 300-308. 
Table $4 F_{\mathrm{ST}} \pm \mathrm{SE}(\theta$ of Weir \& Cockerham, 1984) for a spatially hierarchical analysis of the host plant (Silene latifolia) populations. The number of populations in each group analysed is indicated by $N$. The Strasbourg region is represented by a single population, therefore no $F_{\mathrm{ST}}$ for that region could be calculated. Data are given without the Kembs population

\begin{tabular}{llc}
\hline Regions & $N$ & $\theta \pm \mathrm{SE}$ \\
\hline All populations & 8 & $0.076 \pm 0.016^{* * * *}$ \\
Region of Basle & 5 & $0.019 \pm 0.007^{* *}$ \\
Region of Zurich & 2 & $0.017 \pm 0.021$ \\
Among Basle, Zurich & 3 & $0.113 \pm 0.028^{* * *}$ \\
and Strasbourg regions & & \\
\hline
\end{tabular}

$* * P<0.01, * * * P<0.001$.

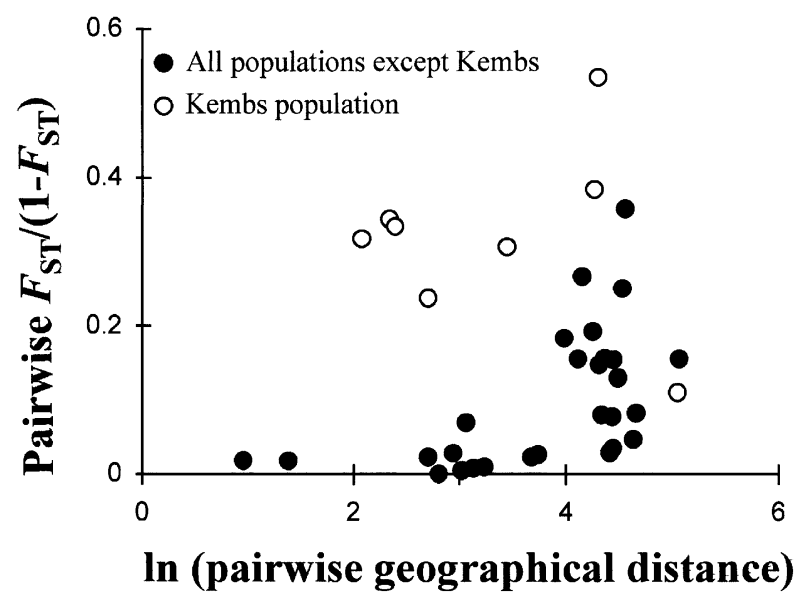

Fig. 2 Isolation by distance plotting pairwise $F_{\mathrm{ST}} /\left(1-F_{\mathrm{ST}}\right)$ against pairwise geographical distance between nine populations of Silene latifolia. The relationship was tested with a Mantel test using 10000 permutations. This relationship is highly significant $(P=0.005)$.

0.196: McCauley, 1997). The Kembs population was highly distinct from all others, particularly at the $P g i$ locus. This suggests either a different linkage relationship between Pgi and selected loci in this population, or a new colonization or founder event. Young populations of this species are more genetically distinct, with higher $F_{\text {ST }}$ values than long-established ones (McCauley et al., 1995).

We found no isolation by distance for all our populations when we included Kembs. To determine whether the other populations in our metapopulation, i.e. those with less distinctive genetical profiles, behaved following normal metapopulation processes, we eliminated all data from the Kembs population from all other analyses. We found significant isolation by distance for the remaining populations without Kembs (Fig. 2). This implies gene flow along the Rhine Valley, although this pattern can be masked by the presence of a single population that differs strongly from the others. Indeed, separating the plant populations into three regions, we found less variation within than among regions (Table 4).

Fungal populations were strongly differentiated (Table 2) with no pattern of isolation by distance. With the exception of the Marthalen and Neerach populations, which contained the same fixed multilocus genotype, no two populations had a multilocus genotype in common (Table 5). Strong differentiation caused by drift is expected among small populations, and drift effects will be stronger with a selfing breeding system, as discussed above. Differential selection pressures in different populations will also contribute to genetic differentiation. There is a genetical basis for host resistance to this parasite (Alexander, 1989), so different host-plant populations may exert different selection pressures on their fungal populations.

\section{Comparing host and parasite population differentiation}

The overall differentiation among populations was highly significant for both host and parasite populations, but far larger for the parasites. This implies less gene flow among parasite than host populations.

Here, we compare genetic structure of a highly selfing parasite and a strictly outcrossing, dioecious host, and using different types of markers, microsatellites and

Table 5 Frequencies of parasite (Microbotryum violaceum) multilocus genotypes identified with microsatellite markers in five populations. Multilocus genotypes in bold type are heterozygous for at least one locus

\begin{tabular}{|c|c|c|c|c|c|c|c|c|c|}
\hline \multirow[b]{2}{*}{ Parasite populations } & \multicolumn{9}{|c|}{ Multilocus genotypes } \\
\hline & $a$ & $b$ & $c$ & $d$ & $e$ & $f$ & $g$ & $\boldsymbol{h}$ & $i$ \\
\hline Neerach & 1 & & & & & & & & \\
\hline Weiningen & & 0.26 & 0.74 & & & & & & \\
\hline Ray & & & & 0.4 & 0.2 & 0.4 & & & \\
\hline
\end{tabular}


allozymes, respectively. Microsatellites are more likely to be neutral than allozymes, and mutate at a higher rate $\left(10^{-5}-10^{-2}\right)$ (Amos et al., 1996). Slatkin (1995) predicts that mutation mode and rate influence the determination of population substructure. Theory predicts that $F_{\mathrm{ST}}$ will be lower when estimated with markers with higher mutation rates, such as microsatellites (Slatkin, 1995; Rousset, 1996), and this is supported by data (Estoup et al., 1998). Here, we found $\approx 12$-fold greater differentiation of parasite populations, using microsatellites, than host populations, using allozymes (Table 2). Therefore, the difference observed between host and parasite population structure differs in the opposite direction to that expected based solely on the nature of the markers.

The large difference between population structure of the host plant and fungal pathogen can be explained by several nonmutually exclusive processes. Plant migration can occur either by seeds or pollen, whereas fungal dispersal only occurs via pollinators. Pollen-mediated gene flow is greater than that of seed flow (McCauley, 1997), but pollinators discriminate against diseased plants (Shykoff \& Bucheli, 1995) and so are less likely to transport fungal spores than host pollen. Selection operating on host plants and fungal parasites may also have different effects on the distribution of variation at our marker loci because of the contrasting breeding systems. Whereas the host plant is an obligate outcrosser, the fungal pathogen has a mixed mating system, but is highly selfing (Baird \& Garber, 1979; Kaltz \& Shykoff, 1999; Bucheli, unpubl. data). Selection on the parasites will more readily homogenize variation at neutral marker loci because the mating system restricts recombination.

\section{Coevolutionary outcomes}

Evolutionary rates of parasites should usually be faster than those of their hosts (Hamilton et al., 1990). However, differential patterns of migration and gene flow can equalize or even reverse this asymmetry in evolutionary rates between host and parasite (Thompson, 1994; Gandon et al., 1996). When parasites migrate less than their hosts within a host-parasite metapopulation, parasites may be at a coevolutionary disadvantage, less able to infect their sympatric hosts than allopatric hosts (Gandon et al., 1996).

Migration rates are difficult to measure, and are usually estimated from genetic population structure. This requires assumptions about the relationship between migration and gene flow. Genetic population differentiation is influenced by reproductive system and population size, as well as migration patterns. Here, we found far higher genetic population structure among parasite than host populations, implying more restricted gene flow of parasites than hosts. Thus, one might predict that the hosts have a coevolutionary advantage. Indeed, fungal strains are on average more infectious on allopatric than on their own sympatric host plants (Kaltz et al., 1999). In a different host-parasite system, Dybdahl \& Lively (1996) found higher differentiation of snail host than trematode parasite populations, and a pattern of local adaptation of the parasite (Lively, 1989). In this case parasites adapt to changes in host resistance faster than hosts respond.

Fungal strains from the related host plant $S$. dioica are more outcrossing and show significantly less differentiation among populations than those from S. latifolia used in this study (Bucheli, unpubl. data). A test of this species revealed that sympatric plants were more susceptible to their local fungi than were plants transplanted from other populations in some, but not all cases (Carlsson-Granér, 1997). Therefore, the difference in mating system of the two pathogens may strongly influence the coevolutionary interaction.

\section{Acknowledgements}

We thank Denis Couvet, Sylvain Gandon, Bernard Godelle, Oliver Kaltz, Yannis Michalakis, Anders Pape Møller, Nicolas Mouquet, Mike Singer and two anonymous reviewers for constructive discussion and comments. This work was supported by Federal Research Institute Grant and Swiss National Science Foundation Grant 31-33638.92.

\section{References}

ALEXANDER, H. M. 1989. An experimental field study of anthersmut disease of Silene alba caused by Ustilago violacea: genotypic variation and disease incidence. Evolution, 43, 835-847.

AMOS, W., SAWCER, S. J., FEAKES, R. W. AND RUBINSZTEIN, D. C. 1996. Microsatellites show mutational bias and heterozygote instability. Nature (Genet.), 13, 390-391.

ANTONOVics, J., THRALl, P., JAROSZ, A. M. AND STRATTON, D. 1994. Ecological genetics of metapopulations: the SileneUstilago plant-pathogen system. In: Real, L. A. (ed.) Ecological Genetics, pp. 146-170. Princeton University Press, Princeton, NJ.

ANTONOVics, J., STRATton, D., Thrall, P. H. AND JAROSZ, A. M. 1996. An anther-smut disease (Ustilago violacea) of fire-pink (Silene virginica): its biology and relationship to the anthersmut disease of white campion (Silene alba). Am. Midl. Nat., 135, 130-143.

BAIRD, M. L. AND GARBER, E. D. 1979. Genetics of Ustilago violacea. V. Outcrossing and selfing in teliospore inocula. Bot. Gaz., 140, 89-93.

BAKER, H. G. 1947. Infection of species of Melandrium by Ustilago violacea (Pers.) Fuckel and the transmission of the resultant disease. Ann. Bot., 11, 333-338. 
BUCHELI, E., GAUTSCHI, B. AND SHYKOFF, J. A. 1998. Isolation and characterisation of microsatellite loci in Microbotryum violaceum. Mol. Ecol., 7, 665-666.

CARLSSON-GRANÉR, U. 1997. Anther-smut disease in Silene dioica. Evolution, 51, 1416-1426.

DAY, A. W. 1980. Competition and distribution studies of genetically marked strains of Ustilago violacea in the same host plant. Bot. Gaz., 141, 313-320.

DIAS, P. 1996. Sources and sinks in population biology. Trends Ecol. Evol., 11, 326-330.

DYBDAHL, M. F. AND LIVELY, C. M. 1996. The geography of coevolution: comparative population structures for a snail and its trematode parasite. Evolution, 50, 2264-2275.

ESPIAU, C., RIVERRE, D., BURDON, J. J., GARTNER, S., DACLINAT, B., HASAN, S. AND CHABOUDEZ, P. 1998. Host-pathogen diversity in a wild system: Chondrilla juncea-Puccinia chondrillina. Oecologia, 113, 133-139.

ESTOUP, A., ROUSSET, F., MICHALAKIS, Y., CORNUET, J.-M., ADRIAMANGA, M. AND GUYOMARD, R. 1998. Comparative analysis of microsatellite and allozyme markers, a case study investigating microgeographic differentiation in brown trout (Salmo trutta). Mol. Ecol., 7, 339-353.

GANDON, S., CAPOWIEZ, Y., DUBOIS, Y., MICHALAKIS, Y. AND OLIVIERI, I. 1996. Local adaptation and gene-for-gene coevolution in a metapopulation model. Proc. R. Soc. B, 263, 1003-1009.

GOUDET, J. 1995. A computer program to calculate $F$-statistics. J. Hered., 86, 485-486.

Hamilton, w. D., AXelrod, R. AND tanese, R. 1990. Sexual reproduction as an adaptation to resist parasites. Proc. Natl. Acad. Sci. U.S.A., 87, 3566-3573.

KALTZ, O. AND SHYKOFF, J. A. 1998. Local adaptation in hostparasite systems. Heredity, 81, 361-370.

KALTZ, O. AND SHYKoFF, J. A. 1999. Selfing versus outcrossing propensity of the fungal pathogen Microbotryum violaceum across Silene latifolia host plants. J. Evol. Biol., 12, in press.

KALTZ, O., GANDON, S., MICHALAKIS, Y. AND SHYKOFF, J. A. 1999. Local maladaptation of the anther-smut fungus Microbotryum violaceum on its host plant Silene latifolia: evidence from a cross-inoculation experiment. Evolution, 53, in press.

LIVELY, C. M. 1989. Adaptation by a parasitic trematode to local populations of its snail host. Evolution, 43, 1663-1671.

MARTINEZ, J. G., SOLER, J. J., SOLER, M., MøLLER, A. P. AND BURKE, T. 1999. Comparative population structure and gene flow of a brood parasite, the great-spotted cuckoo (Clamator glandarius) and its host, the magpie (Pica pica). Evolution, in press.

MCCAULEY, D. E. 1997. The relative contributions of seed and pollen movement to the local genetic structure of Silene alba. J. Hered., 88, 257-263.

MCCAUlEY, D. E., RAVEILl, J. AND ANTONOviCS, J. 1995. Local founding events as determinants of genetic structure in a plant metapopulation. Heredity, 75, 630-636.

mcDermott, J. M. AND mcdonALD, B. A. 1993. Gene flow in plant pathosystems. Ann. Rev. Phytopath., 31, 353-373.

MICHALAKIS, Y. AND EXCOFFIER, L. 1996. A generic estimation of population subdivision using distances between alleles with special reference for microsatellite loci. Genetics, 142, 1061-1064.
MICHALAKIS, Y., SHEPPARD, A. W., NOËL, V. AND OLIVIERI, I. 1994. Population structure of a herbivorous insect and its host plant on a microgeographic scale. Evolution, 47, 1611-1616.

MUlveY, M., AHO, J. M. AND LYDEARD, C. 1991. Comparative population genetic structure of a parasite (Falcioloides magna) and its definitive host. Evolution, 45, 1628-1640.

NADLER, S. A. 1995. Microevolution and the genetic structure of parasite populations. J. Parasitol., 81, 395-403.

NORDBORG, M., CHARLESWORTH, B. AND CHARLESWORTH, D. 1996. Increased levels of polymorphism surrounding selectively maintained sites in highly selfing species. Proc. R. Soc. $B, 263,1033-1039$.

PARKER, M. A. 1988. Disequilibrium between disease-resistance variants and allozyme loci in an annual legume. Evolution, 42, 239-247.

PASTEUR, N., PASTEUR, G., BONHOMMe, F., CATAlAN, J. AND BRITTON-DAVIDIAN, J. 1987. Manuel Technique de Génétique par Electrophorèse des Protéines, 1st edn. TEC \& DOC Lavoisier, Paris.

PRENTICE, H. C. AND GILES, B. E. 1993. Genetic determination of isozyme variation in the bladder campions, Silene uniflora and S. vulgaris. Hereditas, 118, 217-227.

PRICE, P. W. 1980. Evolutionary Biology of Parasites. Princeton University Press, Princeton, NJ.

RAYMOND, M. AND ROUSSET, F. 1995. GENEPOP (version 1.2): population genetics software for exact tests and ecumenicism. J. Hered., 86, 248-249.

RICE, W. R. 1989. Analyzing tables of statistical tests. Evolution, 43, 223-225.

Roche, B. M., AleXANDER, H. M. AND MALTBy, A. D. 1995. Dispersal and disease gradients of anther-smut infection of Silene alba at different life stages. Ecology, 76, 1863-1871.

ROUSSET, F. 1996. Equilibrium values of measures of population subdivision for stepwise mutation processes. Genetics, 142, 1357-1362.

ROUSSET, F. AND RAYMOND, M. 1997. Statistical analyses of population genetic data: new tools, old concepts. Trends Ecol. Evol., 12, 313-317.

SHYKOFF, J. AND BUCHELI, E. 1995. Pollinator visitation patterns, floral rewards and the probability of transmission of Microbotryum violaceum. J. Ecol., 83, 189-198.

SLATKIN, M. 1985. Gene flow in natural populations. Ann. Rev. Ecol. Syst., 16, 393-430.

SLATKIN, M. 1995. A measure of population subdivision based on microsatellite allele frequencies. Genetics, 139, 457-462.

SOLTis, D. E. and Soltis, P. S. 1989. Isozymes in Plant Biology. Chapman and Hall, London.

STEPHAN, W., WIEHE, T. H. E. AND LENZ, M. W. 1992. The effect of strongly selected substitutions on neutral polymorphism: analytical results based on diffusion theory. Theor. Pop. Biol., 41, 237-254.

SWOFFORD, D. L. AND SELANDER, R. B. 1981. BIOSYS-1: A FORTRAN program for the analysis of allelic variation in genetics. J. Hered., 72, 281-283.

ThOMPSON, J. N. 1994. The Coevolutionary Process. University of Chicago Press, Chicago.

WEIR, B. S. AND COCKERHAM, C. C. 1984. Estimating $F$-statistics for the analysis of population structure. Evolution, 38, 13581370 .

(C) The Genetical Society of Great Britain, Heredity, 82, 300-308. 